\title{
Assessing risk behaviours in the Iranian general population: results from the Iranian Mental Health Survey
}

\author{
Masoumeh Amin-Esmaeili, ${ }^{1,2}$ Shahab Baheshmat, ${ }^{3,2}$ Mohammad Javad Tarrahi, ${ }^{4}$ Seyed-Abbas Motevalian, ${ }^{5}$ Vandad Sharifi, ${ }^{6}$ Ahmad Hajebi, ${ }^{7}$ Ramin \\ Mojtabai ${ }^{1}$ and Afarin Rahimi-Movaghar ${ }^{2 *}$
}

${ }^{1}$ Department of Mental Health, Johns Hopkins University, Baltimore, Maryland, United States of America. ${ }^{2}$ Iranian National Centre for Addiction Studies, Tehran University of Medical Sciences, Tehran, Islamic Republic of Iran. ${ }^{3}$ Department of Neuroscience and Addiction Studies, School of Advanced Technologies in Medicine (SATiM), Tehran University of Medical Sciences, Tehran, Islamic Republic of Iran. ${ }^{4}$ Department of Epidemiology and Biostatistics, School of Health, Isfahan University of Medical Sciences, Isfahan, Islamic Republic of Iran. ${ }^{5}$ Department of Epidemiology, School of Public Health, Iran University of Medical Sciences, Tehran, Islamic Republic of Iran. ${ }^{6}$ Department of Psychiatry, Tehran University of Medical Sciences, Tehran, Islamic Republic of Iran. ${ }^{7}$ Research Center for Addiction and Risky Behavior, Psychiatric Department, Iran University of Medical Sciences, Tehran, Islamic Republic of Iran. (Correspondence to: Afarin Rahimi-Movaghar: rahimia@sina.tums.ac.ir)

\begin{abstract}
Background: The Islamic Republic of Iran is a majority Muslim country, with a culturally low acceptance of high-risk behaviours.

Aims: To investigate co-occurrence of risk behaviours in the Iranian general population.

Methods: This was a cross-sectional study. Data were obtained from a random subsample of 3508 participants in the Iranian Mental Health Survey conducted in 2011 who completed a self-administered questionnaire about risk behaviours. The latent class analysis was performed on 7 behaviours consisting of cigarette smoking, alcohol consumption, opium use, use of other illicit drugs, having multiple sexual partners, imprisonment, and running away from home. Unordered multinomial logistic regression was performed to examine characteristics of participants in the latent classes.

Results: In the past 12 months, the rates of cigarette smoking, alcohol consumption, opium use, and use of other illicit drugs were $19.4 \%, 6.3 \%, 4.4 \%$, and $4.2 \%$, respectively. Three classes were identified: 1 , a large class with low prevalence of risk behaviours [89.2\%; 95\% confidence interval (CI): 88.2-90.2\%]; 2, high prevalence of all risk behaviours except drug use (6.1\%; 95\% CI: 5.3-6.9\%); and 3, high prevalence of all risk behaviours (4.7\%; 95\% CI: 4.1-5.5\%). Men and individuals with psychiatric disorders were over-represented in both classes 2 and 3.
\end{abstract}

Conclusion: Alcohol consumers and opium users were at risk of other risky behaviours.

Keywords: epidemiology, latent class analysis, comorbidity, opioid-related disorders, cannabis.

Citation: Amin-Esmaeili M; Baheshmat S; Tarrahi MJ; Motevalian SA; Sharifi V; Hajebi A; et al. Assessing risk behaviours in the Iranian general population: results from the Iranian Mental Health Survey. East Mediterr Health J. 2021;27(10):953-961. https://doi.org/10.26719/emhj.21.029

Received: 02/06/20; accepted: 26/05/21

Copyright (๑) World Health Organization (WHO) 2021. Open Access. Some rights reserved. This work is available under the CC BY-NC-SA 3.0 IGO license (https://creativecommons.org/licenses/by-nc-sa/3.o/igo)

\section{Introduction}

Illicit drug use generally occurs with other risk behaviours and together, they contribute to several medical and psychological morbidities $(1,2)$, socioeconomic add versity (3), and even a high rate of mortality (4). The Iss lamic Republic of Iran has a Muslim majority population. Consumption of alcohol and extramarital sexual relationships are culturally unacceptable for most of the population and illegal. While opium has been the main drug of use in the country for decades, the use of other illicit drugs is stigmatized (5). Nevertheless, the use of synthett ic drugs in the country has been on the rise (6).

Few epidemiological studies have investigated the prevalence and correlates of high-risk behaviours in the Islamic Republic of Iran, and these studies have focused on a specific population at a provincial level. For instance, several studies have investigated high-risk behaviours among university students, and $2.5-7.7 \%$ of the students were assigned to a high-risk group with a high probability of illicit drug use $(7,8)$. To the best of our knowledge, there has been no national epidemiological assessment of risk behaviours in the general Iranian population. Improving estimates of these behaviours in the population and their correlation patterns has important implications for identifying at-risk population groups and improving targeted preventive and healthcare policies for those who are most at risk.

One of the major challenges in estimating the prevalence of risk behaviours in population surveys is the respondents' reluctance to disclose these behaviours because of stigma, social-desirability response bias, and in some cases, concerns regarding the legal ramifications of such disclosures. In the past research, several approaches have been used to improve reporting of highrisk behaviours in population surveys (9). One of the methods attempted to improve respondents' privacy by administering self-report questionnaires that allowed the respondents to answer sensitive questions without disclosing their responses to the interviewer (10).

In the current study, we aimed to describe the prevalence of risk behaviours in the general population using data drawn from the Iranian Mental Health Survey 
(IranMHS) (11). More specifically, we aimed to identify the most at-risk groups using latent class analysis (LCA). This method was applied in prior research for defining patterns of substance use and other risk behaviours in several national surveys in the United States of America (12) and the United Kingdom of Great Britain and Northern Ireland (13) as well as in the Iranian high school and university students (11). We aimed to classify the Iranian general population according to the pattern of 7 risk behaviours by LCA and to characterize the classes with regard to other variables.

\section{Methods}

\section{Study design and population}

Data on risk behaviours were derived from a random subsample of the IranMHS. IranMHS was conducted in 2011 on a representative sample of the Iranian population aged 15-64 years. The primary aim of the IranMHS was to assess the prevalence of psychiatric disorders, outpatient and inpatient service utilization, and the cost of mental illnesses among Iranians aged 15-64 years. The details of the design and protocol of the survey are published elsewhere (14).

\section{Measurements}

Data on sociodemographic characteristics and psychiatric diagnoses were collected through face-to-face interviews. Psychiatric diagnoses were ascertained using Composite International Diagnosis Interview version 2.1, CIDI 2.1, a structured diagnostic interview based on Diagnostic and Statistical Manual, 4th edition (15). Sevv eral psychiatric disorders were assessed in the IranMHS: major depressive disorder, dysthymia, bipolar I disorder, panic disorder (with and without agoraphobia), agoraphobia without panic, obsessive-compulsive disorder, social phobia, post-traumatic stress disorder, and alcohol and other substance use disorders. The life-threatening events were drawn from screening questions of the post-traumatic disorder section (K section) of Composite International Diagnostic Interview 2.1, which provides a comprehensive list of stressful life events. The participants were asked if they had a life-threatening stressful event in their lifetime and whether the stress was sustained in the 12 months prior to the interviews.

\section{Data collection}

All questions were answered using paper and pencil. Along with data collected through face-to-face interviews to assess psychiatric disorders in this national survey, a self-administered questionnaire for risk behaviours was randomly administered to half of the respondents, with a response rate of $76 \%$. This questionnaire included: frequency of cigarette smoking; alcohol consumption; use of opium or sukhteh (opium dross), shireh (condensed extract of opium dross), heroin or crack of heroin (16), cannabis, methamphetamine, ecstasy, methylphenidate without a prescription, medicinal opioids without a prescription (methadone/buprenorphine, tramadol, codeine preparations), and benzodiazepines without a prescription; number of sexual partners in the past 12 months; and history of imprisonment and running away from home.

The self-administered questionnaire was placed in the middle of the interview package. The interviewers helped respondents with a low level of education to read the questions but were not allowed to see their responses. For those who were illiterate, the questions were answered through an interview. The participants were instructed to put the completed questionnaires into a ballot-type box. Interviewers assured the respondents that the box would be sent directly to the survey headquarters and that the interviewer would not know their responses. After recruiting all participants in each province, the closed boxes were sent to the survey centre and opened by the supervisors. The self-report questionnaires did not include the name and identity of the respondents and were linked to the main survey only through an alphanumeric code. The survey protocol was approved by the Ethics Committee of Tehran University of Medical Sciences (no. IR.TUMS.REC.1394.1900). All ethical issues including obtaining informed consent and establishing confidentiality during the interview were considered carefully by the research team.

\section{Statistical analysis}

We calculated prevalence estimates and 95\% confidence intervals (Cis) for use of substances and other risk behaviours. The prevalence of risk behaviours was estimated using the same survey weight utilized in the IranMHS (14). It was a joint product of the inverse probability of unit selection into the sample (w1), nonresponse weights (w2), and post-stratification weights (w3). We used LCA to categorize individuals into distinct classes based on their responses to questions regarding the 7 risk behaviours: (1) smoking a cigarette at least once a month in the past 12 months; (2) alcohol consumption in the past 12 months; (3) opium use in the past 12 months; (4) use of any other illicit drugs in the past 12 months, including cannabis, shireh, heroin or crack of heroin, methamphetamine, and ecstasy; (5) having > 1 sexual partner in the past 12 months; (6) imprisonment; and (7) running away from home. Since opium has traditionally been used in the Islamic Republic of Iran for centuries and is considered to have a low-risk profile and less stigma than other illicit drugs (17), we separated opium use from other illicit drugs for this analysis.

The LCA model produced 2 sets of parameters: (1) prevalence of latent classes in the population; and (2) item response probabilities for each class, which was the likelihood of particular responses to particular questions, conditional to membership in a specific latent class. We ran the model with 15000 iterations and 100 repetitions for each analysis to ensure reliability of the results. The Bayesian Information Criterion (BIC) and the Akaike's Information Criterion (AIC) were used to identify the model with the best fit. Interpretability and parsimony were also considered in the choice of model.After selecting 
the final model, the probability of class membership was regressed on demographic characteristics, stressful life-threatening events, and diagnosis of psychiatric disorders to identify the correlates of risk behaviour in this population. Odds ratios and $95 \%$ CIs were calculated compared to a baseline class generated through LCA. All analyses were performed using $\mathrm{R}$ programming language version 2.14.2 and STAT version 15 (Stata Corp., College Station, Texas, United States of America).

For the estimation of latent class and latent class regression models, we used the polytomous variable LCA package of R statistical programming (18). For comparison of classes in the LCA model, class membership was considered as a nominal variable. An unordered multinomial logistic regression was performed to determine the correlates of membership to each of the 3 classes. In this regression model, the low-risk class was considered as the reference group.

\section{Results}

A total of 3508 individuals (1546 male and 1962 female) completed the self-report questionnaire, with a response rate of $76.7 \%$. The mean (standard deviation) age of the participants was 32.78 (11.90) years. The majority were married $(70 \%)$ and lived in urban areas $(55.9 \%)$. Only $7.3 \%$ of the respondents were illiterate.

The prevalence of risk behaviours according to the self-administered questionnaire are presented in Table 1. Prevalence of cigarette smoking, alcohol consumption, and opium use at least once in the past 12 months was $19.4 \%, 6.3 \%$, and $4.4 \%$, respectively. Use of other illicit drugs, mainly consisting of opioids other than opium and cannabis, was reported by $4.2 \%$ of the participants. There was no significant difference in reporting substance use among those who completed the questionnaire themselves and those whose questionnaire was completed or seen by the interviewer. There was a large overlap between the use of opium and its derivatives, alcohol, and other illicit drugs (Figure 1). The prevalence of having $>1$ sexual partner in the past 12 months was $4.0 \%$, lifetime imprisonment was $3 \%$ and lifetime running away from home was $2.5 \%$ (Table 1 ).

Table 2 presents the fit indices for the 1- to 6-class LCA models. The 3-class model had the smallest values of AIC and BIC and provided an interpretable model. Table 3 presents the probability of the risk behaviours for participants assigned to each of the 3 classes. Class 1 comprised $89.2 \%$ of the sample, followed by $6.1 \%$ in class 2 and $4.7 \%$ in class 3 . Class 1 had the lowest probability for all risk behaviours and was labelled the low-risk class. Individuals in class 2 showed a high probability for all risk behaviours except for the use of opium and other illicit drugs. The main substance used in this class was alcohol. As such, this class was labelled non-drug-using high-risk class. Class 3 consisted of individuals with a high probability of all 7 high-risk behaviours and was labelled the high-risk class.
Compared to participants in class 1 , those in class 2 were more likely to be male, have a psychiatric disorder, and be exposed to stressful life-threatening events, but less likely to belong to a high socioeconomic group (Table 4). Compared to participants in class 1 , those in class 3 were more likely to be male, older, and have a psychiatric disorder, but less likely to have higher education.

\section{Discussion}

We estimated risk behaviours in the Iranian population using a self-administered measure and explored patterns of risk behaviours using the LCA method. Opioids were the most common illicit drugs used and opium was the most commonly used illicit opioid. A 3-class model was found to provide the best fit for describing patterns of risk behaviours. Our findings suggest that $\sim 89 \%$ of the population could be classified as low risk. Other than smoking cigarettes, the prevalence of the risk behaviours was close to zero in this class. The analyses identified 2 high-risk groups. (1) The non-drug-using high risk class had substantial prevalence of almost all risk behaviours, except use of opium and other illicit drugs. Alcohol consumption was also prevalent in this class. (2) The highrisk class comprised participants with a high prevalence of all risk behaviours, especially opium and illicit drug use. The 2 high-risk groups were distinguishable by their use of opium and other illicit drugs. However, both groups did not differ substantially for other risk behaviours.

Although several studies have investigated the pattern of substance use and risk behaviours, there were inconsistencies in the risk behaviours of interest among the studies. Smoking, binge drinking, illicit drug or polysubstance use, emotional distress, unhealthy diet, lack of appropriate physical activity, and insufficient sleep, all together or in groups, were considered as high-risk behaviours in different studies (19-21). The inconsistency between the target population and the risk behaviours of interest makes it difficult to compare the results of the current study with past research. Most of the available research with the same methodology has been conducted in western countries that have different legal, social and cultural perspectives regarding alcohol and marijuana use. Most studies that have applied the LCA method to classify individuals based on their risk behaviours have focused on substance use. In most of these studies, a large class of individuals with a low prevalence of substance use and a small group of polydrug users were identified $(13,19,21,22)$. Similar to the current study, $<5 \%$ of the participants in a national survey of secondary school students had multiple risk behaviours including polydrug use and emotional distress (21). Another LCA based on a large number of adolescents from 25 European countries identified 4 substance use classes: a large group of nonusers, 2 groups of alcohol and concurrent alcohol and marijuana users, and a small group of polysubstance users (22). Similarly, a study of British adults identified 3 latent classes: a large class with no polydrug use, and 2 small groups with moderate and high prevalence of 


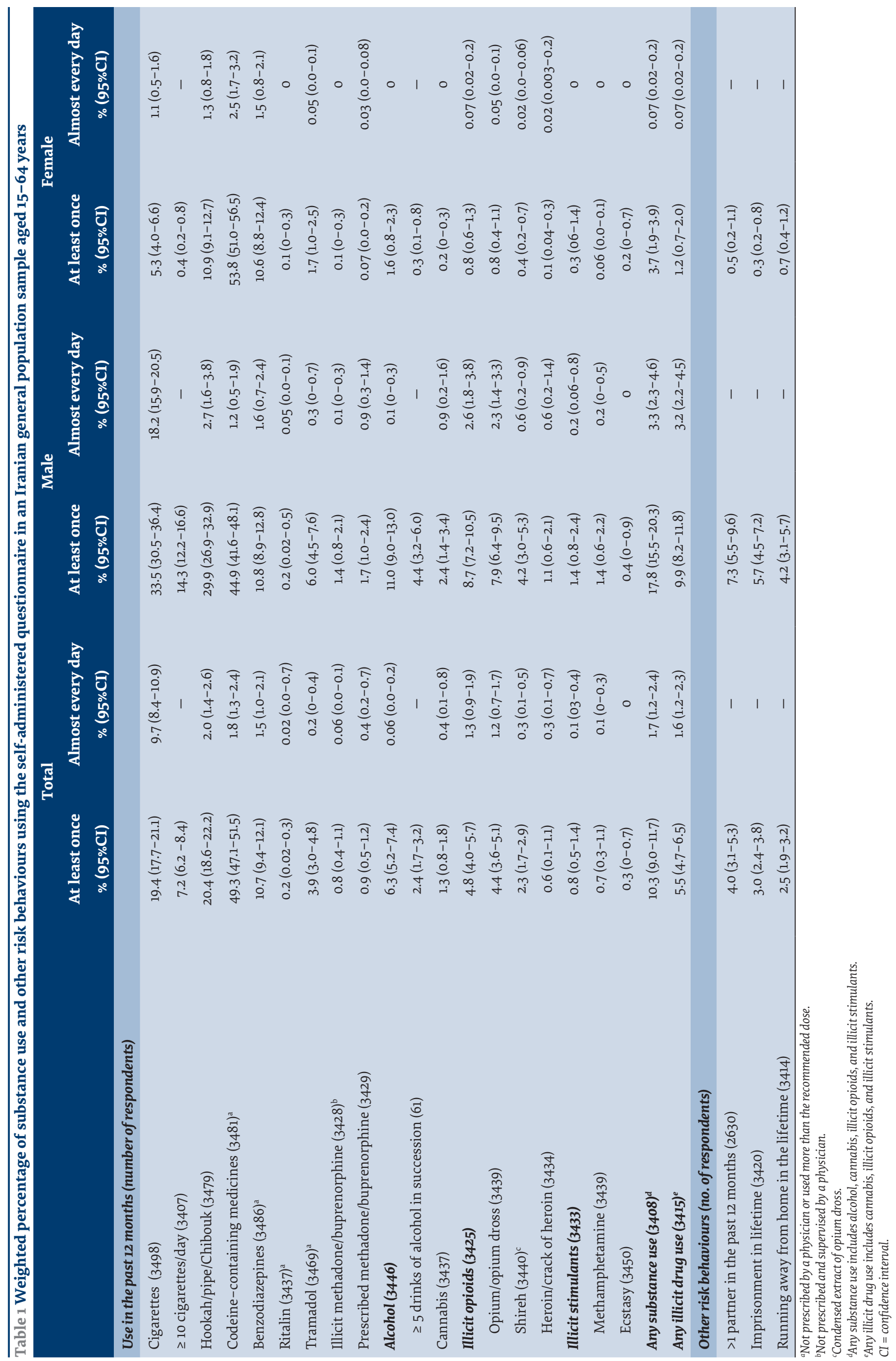




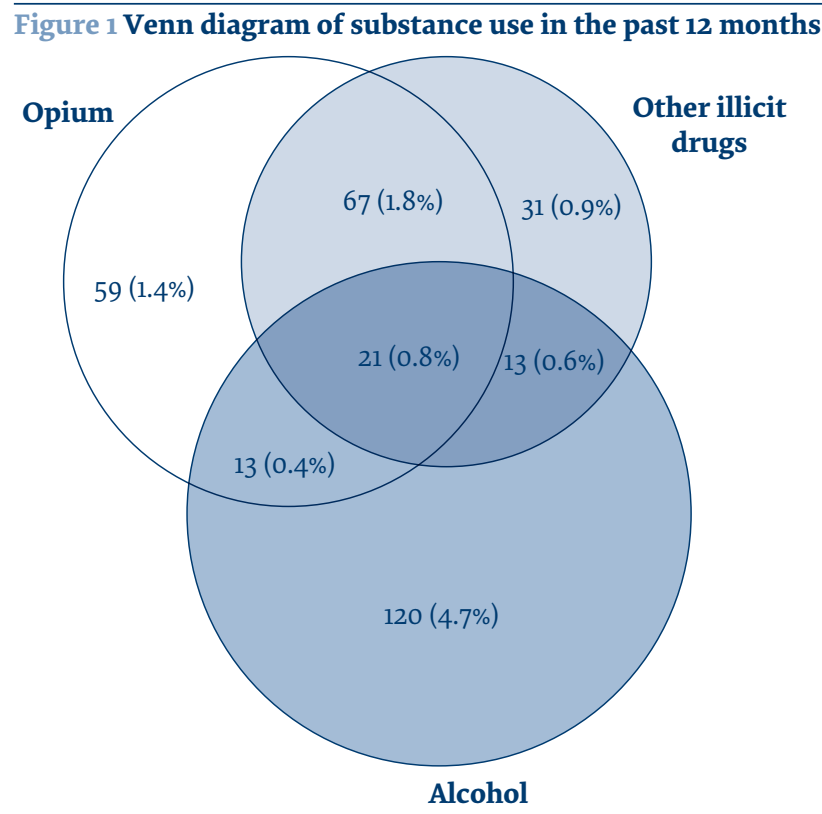

polydrug use (13). The probability of smoking, hazardous alcohol consumption, and mental health problems was higher in the latter 2 groups.

One of the different findings in our study compared with others around the world was that alcohol consumers

\begin{tabular}{|c|c|c|c|c|}
\hline \multicolumn{5}{|c|}{$\begin{array}{l}\text { Table } 2 \text { Summary of fit indices for the LCA model with } 1 \text { to } 6 \\
\text { classes }\end{array}$} \\
\hline Model & $\begin{array}{c}\text { No. of } \\
\text { parameters }\end{array}$ & $\begin{array}{l}\text { Log } \\
\text { likelihood }\end{array}$ & BIC & AIC \\
\hline 1-class & 7 & -4438.6 & 8934.4 & 8891.3 \\
\hline 2-class & 15 & -3822.1 & 7766.6 & 7674.2 \\
\hline 3-class & 23 & -3779.1 & 7745.9 & 7604.1 \\
\hline 4-class & 31 & -3766.3 & 7785.6 & 7594.6 \\
\hline 5-class & 39 & -3755.9 & 7828.7 & 7588.3 \\
\hline 6-class & 47 & -3752.8 & 7899.3 & 7599.4 \\
\hline
\end{tabular}

AIC $=$ Akaike's Information Criterion; BIC $=$ Bayesian Information Criterion; LCA = latent class analysis. were not classified in the large low-risk class, and presented with a high rate of other risky behaviours. This may have been due to the cultural and legal prohibitions against consumption of alcohol, making it similar to other illicit substances in the Islamic Republic of Iran. These associations are concerning given the recent reports showing a rise in alcohol consumption and its associated health consequences in this population (23).

Our study showed that those who engaged in risk behaviours were more likely men and had higher odds of psychiatric disorders. More than $90 \%$ of the highrisk class were male, and nearly $60 \%$ of them had been diagnosed with $\geq 1$ psychiatric disorder in the past 12 months. A review of epidemiological studies in the Islamic Republic of Iran showed that cigarette smoking, alcohol consumption and illicit drug use were significantly more common in men than women (24). The strong association of psychiatric disorders with high-risk behaviours has also been noted previously (25).

It is noteworthy thatopium use, which has traditionally been used for centuries in the Islamic Republic of Iran (26), was associated with the high-risk class. It suggests a new pattern of opium consumption, which appeared in combination with other risk behaviours including other illicit drug use. Earlier research has suggested lower social stigma, lower rate of criminal justice involvement, and psychiatric illness in those who use opium compared to other illicit drugs (5). However, there is some evidence that this pattern may be changing. Recent studies from some Iranian provinces have identified a higher crime rate and prevalence of psychiatric comorbidity in occasional opium users as well as individuals with opium dependence, compared to the non-opium-using population (27). Our findings suggest an increase in polysubstance use among Iranian opium users, which echoes evidence of the increasing trend of polydrug use in other countries $(28,29)$.

Some people had a high probability of certain risk behaviours that could put them at a greater risk of negative health consequences. Multiple sexual partners in combination with other risk behaviours, such as stimulant drug use, could increase the risk of unsafe

Table 3 Prevalence of risk behaviour classes and probability of observed risk behaviours conditional on class membership in the Iranian general population aged 15-64 years

\begin{tabular}{lccc} 
& $\begin{array}{c}\text { Class 1 } \\
\text { (low risk) }\end{array}$ & $\begin{array}{c}\text { Class 2 } \\
\text { (non-drug-using high risk) }\end{array}$ & $\begin{array}{c}\text { Class 3 } \\
\text { (high risk) }\end{array}$ \\
Class prevalence & 0.892 & 0.061 & 0.047 \\
Smoking at least once a month in past 12 months & 0.0532 & 0.4381 & 0.7777 \\
Alcohol consumption, past 12 months & 0.0081 & 0.3304 & 0.2609 \\
Opium use, past 12 months & 0.0061 & 0.0543 & 0.7323 \\
Any illicit drug use, other than opium ${ }^{\mathrm{a}}$, past 12 months & 0.0046 & 0.0000 & 0.6991 \\
> 1 sexual partner, past 12 months & 0.0093 & 0.1564 & 0.1596 \\
Imprisonment during lifetime & 0.0040 & 0.1507 & 0.2600 \\
Running away from home during lifetime & 0.0073 & 0.1036 & 0.1280 \\
\hline
\end{tabular}




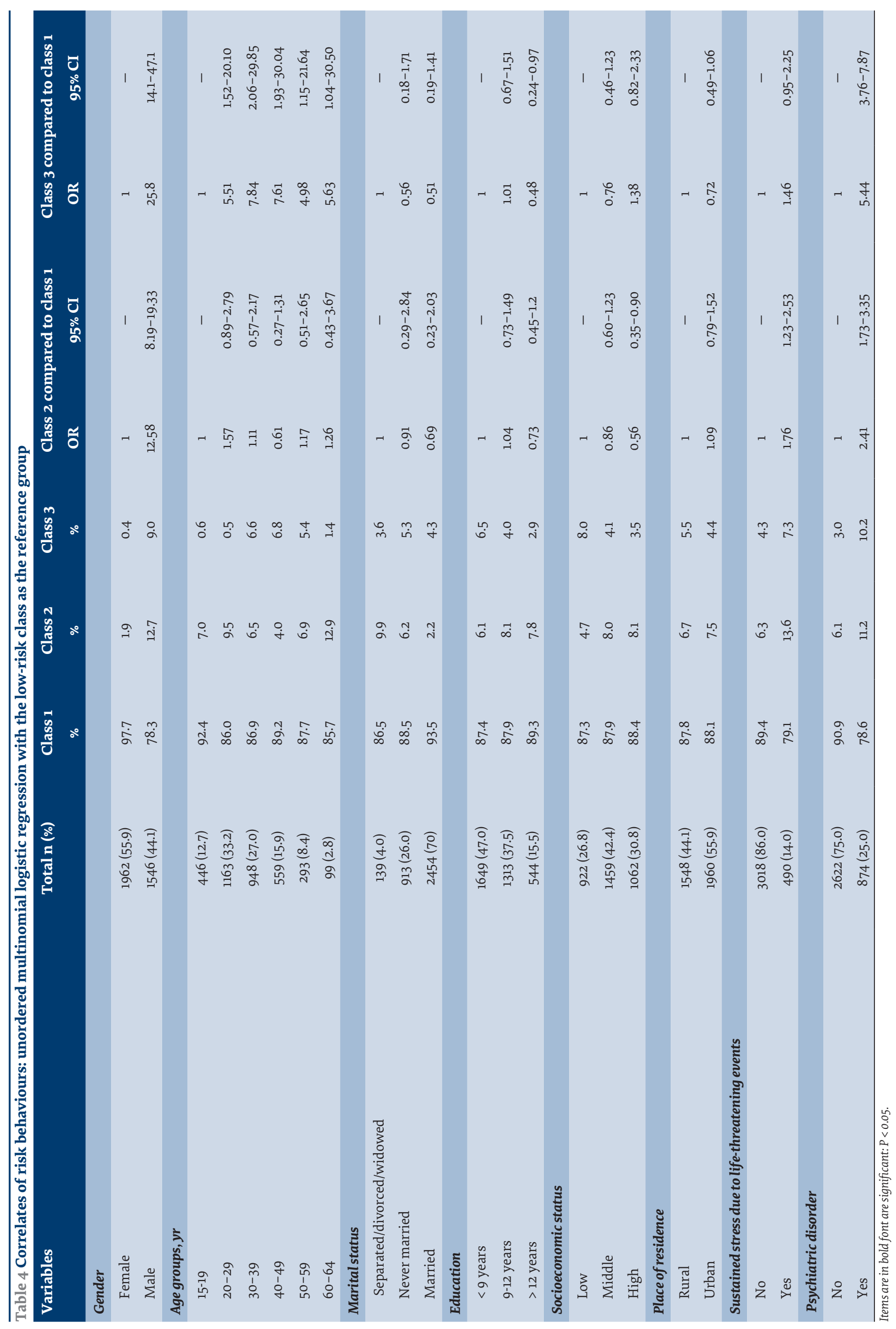


sex and sexually transmitted diseases. The association between illicit drug use, high-risk sexual behaviours, and sexually transmitted and blood-borne infections in Iranian drug users is well documented $(2,30,31)$. The substantial percentage of the general population in either of 2 high-risk groups raises the necessity of providing population-wide preventive interventions (32), as well as screening and therapeutic measures for the population with treatment needs (33).

This study was the first Iranian national study to classify individuals according to their substance use and other risk behaviours. A limitation of our study was the cultural barrier in asking such sensitive questions, especially on sexual relationships. Although we used a self-administered questionnaire to assist the reporting of risk behaviours, social and cultural barriers in responding to sensitive questions, especially regarding sexual behaviour, remained a limitation of our study. We also sought to reduce the impact of such barriers by limiting the number of questions regarding sexual partners and placing this question at the end of the questionnaire.
However, future innovative methods are needed to improve recording these highly sensitive behaviours. Expansion of mHealth, triangulation of different data collection methods, and unintrusive means of assessing risk behaviours may provide new avenues for such assessments (34).

\section{Conclusion}

The present study revealed that the majority of the population did not report high-risk behaviours. However, in the minority, most of the risk behaviours occurred together. Both alcohol consumption and opium use place individuals in this community at elevated risk for other risky behaviours. A substantial percentage of the general population was classified into either of the 2 high-risk groups, which raises the necessity of providing population-wide preventive interventions as well as screening and therapeutic measures for the population with treatment needs. All high-risk behaviours should be addressed in primary prevention efforts.

\section{Acknowledgement}

This study was supported financially by the Iranian Ministry of Health through the contract number 132-1491 and the contract number 89-D-432-143 from Mental Health Research Network to Tehran University of Medical Sciences. The funders had no role in the study design, collection, analysis, or interpretation of the data, writing the manuscript, or the decision to submit the paper for publication.

Funding: None.

Competing interests: None declared.

\section{Évaluation des comportements à risque dans la population générale iranienne : résultats de l'enquête iranienne sur la santé mentale}

\section{Résumé}

Contexte: La République islamique d'Iran est un pays majoritairement musulman, où les comportements à haut risque sont culturellement peu acceptés.

Objectifs : Étudier la co-occurrence des comportements à risque dans la population générale iranienne.

Méthodes : Il s'agissait d'une étude transversale. Les données ont été obtenues auprès d'un sous-échantillon aléatoire de 3508 participants à l'enquête iranienne sur la santé mentale menée en 2011 qui ont rempli un questionnaire d'autoévaluation sur les comportements à risque. L'analyse en classes latentes a été effectuée sur sept types de comportement, à savoir la consommation de cigarettes, d'alcool, d'opium et d'autres drogues illicites, les rapports sexuels avec des partenaires multiples, l'emprisonnement et les fugues. Une régression logistique multinomiale non ordonnée a été réalisée pour examiner les caractéristiques des participants dans les classes latentes.

Résultats : Au cours des 12 derniers mois, les taux de tabagisme par cigarette, de consommation d'alcool, d'opium et d'autres drogues illicites étaient respectivement de 19,4\%,6,3\%,4,4\% et 4,2\%. Trois classes ont été identifiées : 1) une grande classe caractérisée par une faible prévalence des comportements à risque $[89,2 \%$; intervalle de confiance (IC) à $95 \%: 88,2-90,2 \%] ; 2)$ une prévalence élevée de tous les comportements à risque, à l'exception de la consommation de drogues $(6,1 \%$; IC à $95 \%: 5,3-6,9 \%)$; et 3) une prévalence élevée de tous les comportements à risque (4,7\%; IC à $95 \%$ : 4,1-5,5\%). Les hommes et les personnes présentant des troubles psychiatriques étaient surreprésentés dans les classes 2 et 3 .

Conclusion : Les consommateurs d'alcool et d'opium étaient exposés à d'autres comportements à risque. 


\section{تقييم السلو كيات الخطرة لدى عموم السكان في إيران: نتائج مستقاة من دراسة استقصائية عن الصحة النفسية في جمهورية إيران الإسلامية التئية \\ معصو مه أمين إسماعيلى، شهاب باحشمت، محمدجو إد طر احى، سيد عباس متوليان، ونداد شريفى، أحمد حاجبى، رامين مجتبايى، آفرين رحيمى \\ الخلفية: جمهورية إير ان الإسلامية بلد ذو أغلبية مسلمة، وقبوله منخفض للسلوكيات الشديدة الخطورة بحكم خلفيته الثقافية. الأهداف: هدفت هذه الدراسة الى استقصاء حدوث السلوكيات الخطرة بين عموم السكان الإيرانيين.

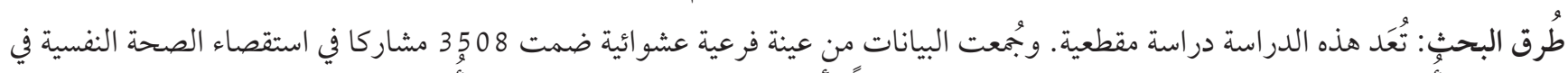

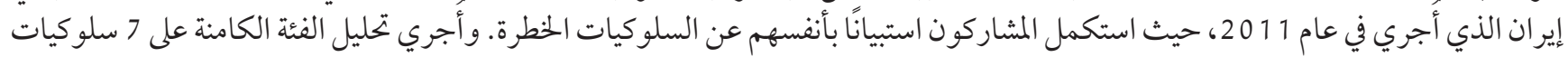

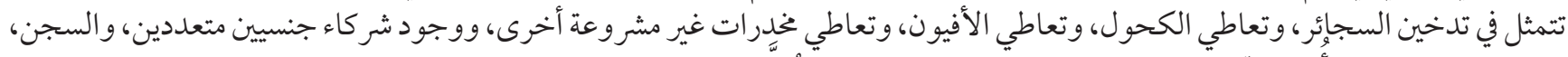

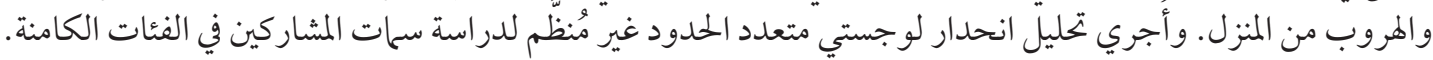

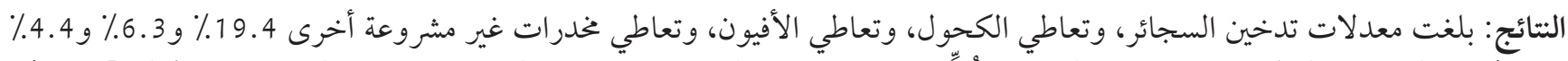

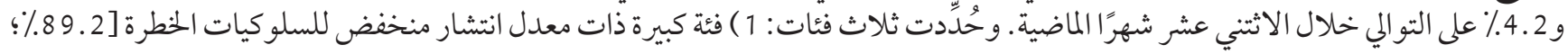

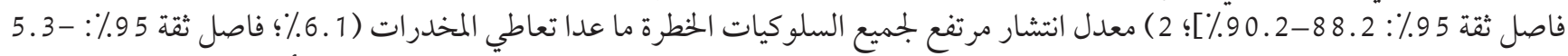

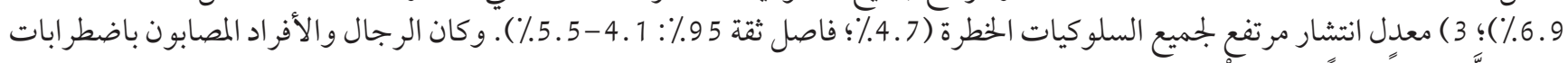

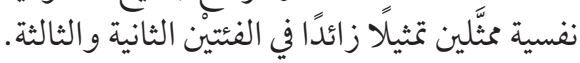

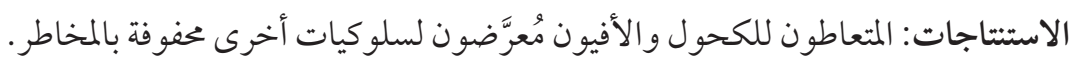

\section{References}

1. Rostam-Abadi Y, Gholami J, Amin-Esmaeili M, Safarcherati A, Mojtabai R, Ghadirzadeh MR, et al. Tramadol use and public health consequences in Iran: a systematic review and meta-analysis. Addiction. 2020 Dec;115(12):1066-76. https://doi.org/10.1111/ add.15059 PMID:32196801

2. Amin-Esmaeili M, Rahimi-Movaghar A, Haghdoost AA, Mohraz M. Evidence of HIV epidemics among non-injecting drug users in Iran: a systematic review. Addiction. 2012 Nov;107(11):1929-38. https://doi.org/10.1111/j.1360-0443.2012.03926.x PMID:22551085

3. White J, Bell S, Batty GD. Association of illicit drug use in adolescence with socioeconomic and criminal justice outcomes in adulthood: prospective findings from a UK national birth cohort. J Epidemiol Community Health. 2020 Sep;74(9):705-9. https:// doi.org/10.1136/jech-2019-213282. PMID:32366585

4. Martin JL, Gadegbeku B, Wu D, Viallon V, Laumon B. Cannabis, alcohol and fatal road accidents. PLoS One. 2017 Nov 8;12(11):e0187320. https://doi.org/10.1371/journal.pone.0187320 PMID: 2911720

5. Mokri A. Brief overview of the status of drug abuse in Iran. Arch Iran Med. 2002;5(3):184-90. http://ams.ac.ir/AIM/0253/0253184. htm

6. Shadloo B, Amin-Esmaeili M, Haft-Baradaran M, Noroozi A, Ghorban-Jahromi R, Rahimi-Movaghar A. Use of amphetamine-type stimulants in the Islamic Republic of Iran, 2004-2015: a review. East Mediterr Health J. 2017 May 1;23(3):245-56. https://doi. org/10.26719/2017.23.3.245 PMID: 2849327

7. Safiri S, Rahimi-Movaghar A, Yunesian M, Sadeghi-Bazargani H, Shamsipour M, Mansournia MA, et al. Subgrouping of risky behaviors among Iranian college students: a latent class analysis. Neuropsychiatr Dis Treat. 2016 Jul 22;12:1809-16. https://doi. org/10.2147/NDT.S107349 PMID:27524898

8. Afrashteh S, Ghaem H, Abbasi-Ghahramanloo A, Tabatabaee HR. Clustering and combining pattern of high-risk behaviors among Iranian university students: a latent class analysis. J Res Health Sci. 2017 Nov 13;17(4):398. PMID:29233953

9. Langhaug LF, Sherr L, Cowan FM. How to improve the validity of sexual behaviour reporting: systematic review of questionnaire delivery modes in developing countries. Trop Med Int Health. 2010 Mar;15(3):362-81. https://doi.org/10.1111/j.13653156.2009.02464.x PMID:20409291

10. Harling G, Gumede D, Mutevedzi T, McGrath N, Seeley J, Pillay D, et al. The impact of self-interviews on response patterns for sensitive topics: a randomized trial of electronic delivery methods for a sexual behaviour questionnaire in rural South Africa. B BMC Med Res Methodol. 2017;17(1):125. https://doi.org/10.1186/s12874-017-0403-8.

11. Sharifi V, Amin-Esmaeili M, Hajebi A, Motevalian A, Radgoodarzi R, Hefazi M, et al. Twelve-month prevalence and correlates of psychiatric disorders in Iran: the Iranian Mental Health Survey, 2011. Arch of Iran Med. 2015 Feb;18(2):76-84. PMID:25644794

12. Tam TW, Mulia N, Schmidt LA. Applicability of Type A/B alcohol dependence in the general population. Drug Alcohol Depend. 2014 May 1;138:169-76. https://doi.org/10.1016/j.drugalcdep.2014.02.698 PMID:24647367 
13. Smith GW, Farrell M, Bunting BP, Houston JE, Shevlin M. Patterns of polydrug use in Great Britain: Findings from a national household population survey. Drug Alcohol Depend. 2011 Jan 15;113(2-3):222-8. https://doi.org/10.1016/j.drugalcdep.20108.010 PMID:20863629

14. Rahimi-Movaghar A, Amin-Esmaeili M, Sharifi V, Hajebi A, Radgoodarzi R, Hefazi M, et al. Iranian mental health survey: design and field proced. Iran J Psychiatry. 2014 Apr;9(2):96-109. PMID:25632287

15. American Psychiatric Association. Diagnostic and statistical manual of mental disorders (4th ed., text rev.). Washington, DC; 2000.

16. Farhoudian A, Sadeghi M, Khoddami Vishteh HR, Moazen B, Fekri M, et al. Component analysis of Iranian crack: a newly abused narcotic substance in Iran. Iran J Pharm Res. 2014 Winter;13(1):337-44. PMID:24734089

17. Rahimi $\square$ Movaghar A, Amin $\square$ Esmaeili M, Hefazi M, Yousefi $\square$ Nooraie R. Pharmacological therapies for maintenance treatments of opium dependence. Cochrane Database Syst Rev. 2013 Jan 31;(1):CDoo7775. https://doi.org/10.1002/14651858.CDoo7775.pub2 PMID:23440817

18. Linzer DA, Lewis JB. poLCA: An R package for polytomous variable latent class analysis. J Stat Software. 2011;42(10):1-29. https:// doi.org/10.18637/jss.v042.i10.

19. Silveira ML, Green VR, Iannaccone R, Kimmel HL, Conway KP. Patterns and correlates of polysubstance use among US youth aged 15-17 years: wave 1 of the Population Assessment of Tobacco and Health (PATH) Study. Addiction. 2019 May;114(5):907-16. https://doi.org/10.1111/add.14547 PMID:30614093

20. Kang J, Ciecierski CC, Malin EL, Carroll AJ, Gidea M, Craft LL, et al. A latent class analysis of cancer risk behaviors among U.S. college students. Prev Med. 2014;64:121-5. doi: 10.1016/j.ypmed.2014.03.023.

21. Noel H, Denny S, Farrant B, Rossen F, Teevale T, Clark T, et al. Clustering of adolescent health concerns: a latent class analysis of school students in New Zealand. J Paediatr Child Health. 2013 Jul;49(11):935-41. https://doi.org/10.1111/jpc.12397 PMID:24704131

22. Göbel K, Scheithauer H, Bräker A-B, Jonkman H, Soellner R. Substance use patterns among adolescents in Europe: a latent class analysis. Subst Use Misuse. 2016 Jul 28;51(9):1130-8. https://doi.org/10.3109/10826084.2016.1160120 PMID:27192400

23. Shokoohi M, Rahimi-Movaghar A, Noroozi A, Karamouzian M. A public health approach to alcohol use and its related harms in Iran. Lancet Public Health. 2019 Apr;4(4):e175-6. https://doi.org/10.1016/S2468-667(19)30038-6 PMID:30954139

24. Rahimi-Movaghar A. A review on the prevalence and the patterns of drug abuse in women in Iran. Soc Welfare 2004 Spring;3(12):203-26 (in Persian). https://www.sid.ir/en/journal/ViewPaper.aspx?id=26672

25. Lai HMX, Cleary M, Sitharthan T, Hunt GE. Prevalence of comorbid substance use, anxiety and mood disorders in epidemiological surveys, 1990-2014: a systematic review and meta-analysis. Drug Alcohol Depend. 2015 Sep 1;154:1-13. https://doi.org/10.1016/j. drugalcdep.2015.05.031 PMID:26072219

26. Jafari S, Rahimi-Movaghar A, Craib K, Baharlou S, Mathias R. Socio-cultural factors associated with the initiation of opium use in Darab, Iran. Int J Ment Health Addiction. 2009;7(2):376-88. https://doi.org/10.1007/s11469-008-9176-y.

27. Najafipour H, Banivaheb G, Sabahi A, Naderi N, Nasirian M, Mirzazadeh A. Prevalence of anxiety and depression symptoms and their relationship with other coronary artery disease risk factors: a population-based study on 5900 residents in Southeast Iran. Asian J Psychiatr. 2016 Apr;20:55-6o. https://doi.org/10.1016/j.ajp.2016.01.004 PMID:27025473

28. Karjalainen K, Kuussaari K, Kataja K, Tigerstedt C, Hakkarainen P. Measuring concurrent polydrug use in general populations: a critical assessment. Eur Addict Res. 2017;23(3):163-9. https://doi.org/10.1159/000477802 PMID:28641293

29. Mammone A, Fabi F, Colasante E, Siciliano V, Molinaro S, Kraus L, et al. New indicators to compare and evaluate harmful drug use among adolescents in 38 European countries. Nordic Stud Alcohol Drugs. 2014;31(4):343-58. https://doi.org/10.2478/nsad-0140027.

30. Amin-Esmaeili M, Rahimi-Movaghar A, Gholamrezaei M, Razaghi EM. Profile of people who inject drugs in Tehran, Iran. Acta Med Iran. 2016 Dec;54(12):793-805. PMID:28120592

31. Rahimi J, Gholami J, Amin-Esmaeili M, Fotouhi A, Rafiemanesh H, Shadloo B, et al. HIV prevalence among people who inject drugs (PWID) and related factors in Iran: a systematic review, meta-analysis and trend analysis. Addiction. 2020 Apr;115(4):60522. https://doi.org/10.1111/add.14853 PMID:31631425

32. Bo A, Hai AH, Jaccard J. Parent-based interventions on adolescent alcohol use outcomes: a systematic review and meta-analysis. Drug Alcohol Depend. 2018 Oct 1;191:98-109. https://doi.org/10.1016/j.drugalcdep.2018.05.031 PMID:30096640

33. Amato L, Mitrova Z, Davoli M. Cochrane systematic reviews in the field of addiction: past and future. J Evid Based Med. 2013 Nov;6(4):221-28. https://doi.org/10.1111/jebm.12067 PMID:24325414

34. Desmond N, Nagelkerke N, Lora W, Chipeta E, Sambo M, Kumwenda M, et al. Measuring sexual behaviour in Malawi: A triangulation of three data collection instruments. BMC Public Health. 2018;18(1):807. https://doi.org/10.1186/s12889-018-5717-X. 